\title{
Annulate Lamellae in Plant Cells : Formation during Microsporogenesis and Pollen Development in Canna generalis Bailey
}

\author{
Ulrich Scheer and Werner W. Franke \\ Department of Cell Biology, Institute of Biology II, \\ University of Freiburg i. Br., BRD
}

Received May 3, 1972

Summary. The occurrence of stacked annulate lamellae is documented for a plant cell system, namely for pollen mother cells and developing pollen grains of Canna generalis. Their structural subarchitecture and relationship to endoplasmic reticulum (ER) and nuclear envelope cisternae is described in detail. The results demonstrate structural homology between plant and animal annulate lamellae and are compatible with, though do not prove, the view that annulate lamellar cisternae may originate as a degenerative form of endoplasmic reticulum.

\section{Introduction}

Stacks of annulate lamellae (AL) are a characteristic feature of various animal cell types, especially during germ cell development, early embryogenesis, and tumorous growth (for references see, e.g., Kessel, 1968; Wischnitzer, 1970; Franke and Scheer, 1971). Stacked AL, however, have not been described for plant cells. This article presents a documentation of the occurrence of typical AL stacks in pollen and pollen mother cells of a Zingiberalean species, Canna generalis.

\section{Material and Methods}

From Canna generalis Bailey grown in the botanical garden, buds of 20 to $30 \mathrm{~mm}$ length were taken. The anthers were immediately immersed in ice cold $2 \%$ glutaraldehyde, buffered with $0.05 \mathrm{M}$ sodium cacodylate to $\mathrm{pH} 7.2$ and containing $0.1 \mathrm{M} \mathrm{KCl}$ and $3 \mathrm{mMCaCl}_{2}$, and were sliced in about $1 \mathrm{~mm}$ thick cross sections. After $1 \mathrm{~h}$ the anther pieces were thoroughly washed in ice cold cacodylate buffer (pH 7.2) and postfixed in $2 \% \mathrm{OsO}_{4}(\mathrm{pH} 7.2$ with the same buffer) in the cold for $2 \mathrm{~h}$. Dehydration was carried out in the cold through an ethanol series. The material was embedded in Epon 812 and sectioned on a Reichert ultramicrotome OmU2. Sections were stained in uranyl acetate and lead citrate and micrographs were taken with an Elmiskop IA.

10 Planta (Berl.), Bd. 107 


\section{Results \\ A. Growing Pollen Grains}

In differentiating pollen grains which are characterized by their extensive wall formation (Fig. 1) cytoplasmic AL occur either as single cisternae or as more or less elaborate stacks (Figs. 1 and 2). They are preferentially, though not exclusively, located in the juxtanuclear region (Figs. 1 and 2). In this cell stage we found up to four cisternae arranged into a stack, often parallel to the nuclear envelope (Fig. 2). Structural data were determined from both tangential and transverse sections. For the calculation of pore frequencies from transverse sections an average section thickness of $700 \AA$ was used (as determined in spot checks interferometrically) as well as the criterion of Barnes and Davis (1959) for defining a pore. The mean inner pore diameter of the AL pore complexes was $700 \AA( \pm 25 \AA)$, and the pore frequency was calculated to be 74 pores per square micron. This is to be compared with the corresponding values determined for the nuclear envelope which are $700 \AA$ ( $\pm 20 \AA$ ) and 25 pores $/ \mu^{2}$ (for a direct comparison see, e.g., Fig. 3). The ultrastructure of the AL pore complexes in this material was identical to that of the pollen mother cells which are described in detail subsequently. Numerous AL pore complexes showed a "classic" central granule (c.f. Pollister et al., 1954; Kessel, 1968). The luminal space of the AL cisternae was frequently continuous with spaces of ER cisternae or inflations, usually in the marginal part of the AL (Figs. 2 and 3). In between the pore complexes the AL membranes sometimes showed ribosomes attached (e.g. Fig. 3). In close association with AL we often noted conspicuous aggregates of small smooth surfaced vesicles (diameters from 50 to $1200 \AA$ ) and groups of highly electron dense clumps, approximately $800 \AA$ in mean diameter, which suggest a finely filamentous subarchitecture with interconnecting threads (Figs. 2 and 3). Situations as, for instance, that shown in the upper part of Fig. 3 (long arrow) suggest a spatial relationship of the small smooth vesicles with AL pore complexes.

Fig. 1. Survey micrograph of developing Canna pollen grain showing the position of annulate lamellae in the juxtanuclear region of the cytoplasm (pairs of arrows). Note the numerous dictyosomes as well as the highly vacuolated cytoplasm. $N u$ nucleolus; $W$ pollen wall. $\times 5000$

Fig. 2. Same material as in Fig. 1. In the immediate vicinity of the nucleus $(N)$ annulate lamellae occur either single (left pair of arrows and arrow in the lower right) or stacked. A transition between $\mathrm{AL}$ and $\mathrm{ER}$ cisternae is indicated by the uppermost arrow. The double arrow points to the "aggregate complex" consisting of dense masses and smooth surfaced vesicles which are closely associated with the AL. Note also vesicular profile in the nucleoplasm (arrowhead in the lower left). Mi mitochondrion. $\times 20000$ 

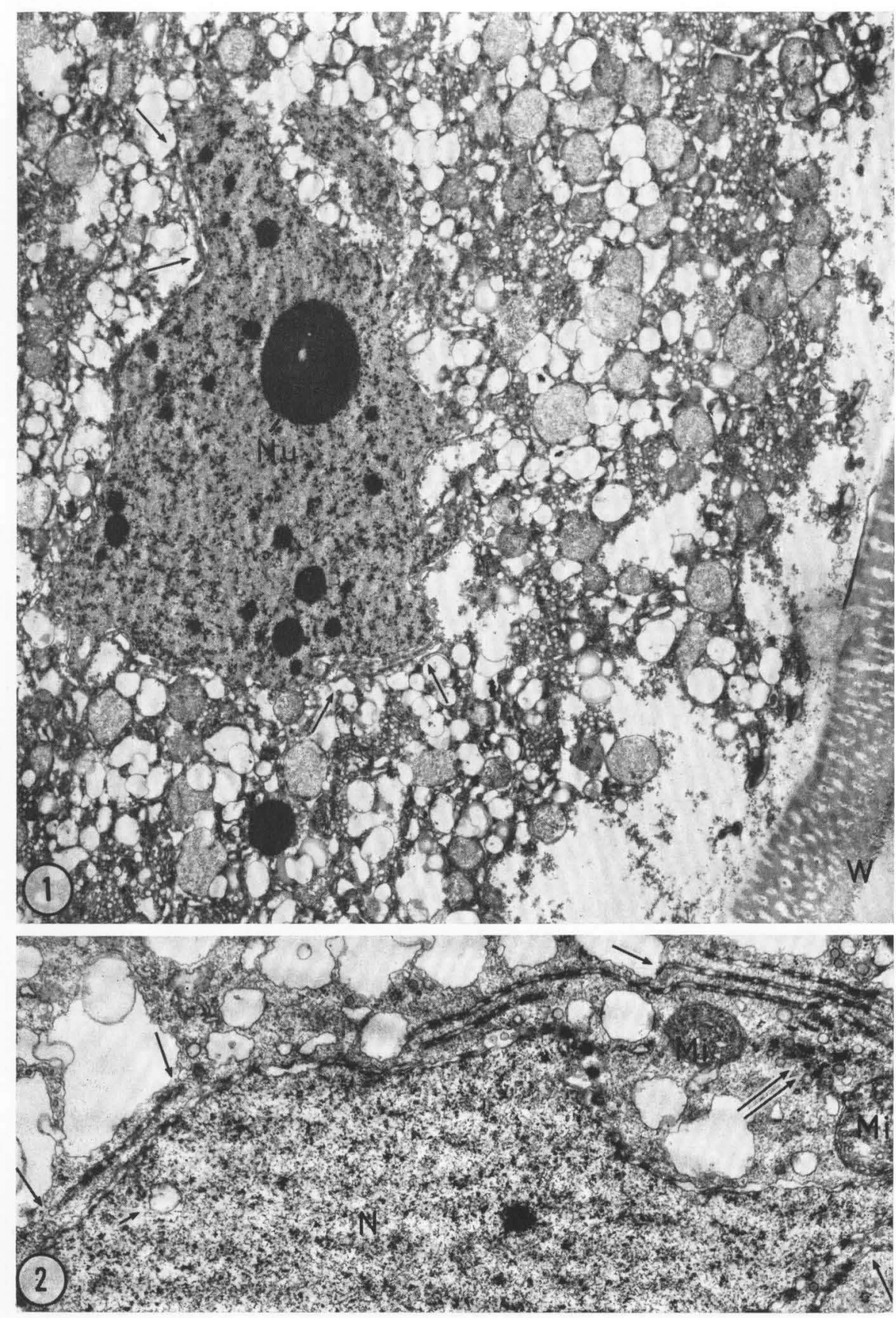

Figs. 1 and 2 


\section{B. Pollen Mother Cells}

Stacks of AL comprising up to six regularly spaced cisternae were found throughout the pollen mother cell cytoplasm (Figs. 4-7). In the present description we only refer to meiotic stages (middle zygotene to pachytene) of early prophase as identified by the form of their synaptinemal complexes (Fig. 9) and by the location of their nucleoli (Fig. 8) as tightly pressed to the inner nuclear membrane (for criteria of stage determination at an electron microscopic level see, e.g., the recent articles of Moens, 1968, and LaCour and Wells, 1972). The AL cisternae showed manifold luminal transitions into the more or less inflated endoplasmic reticulum (ER) system which is basically "rough" in character (Figs. 4-7) as well as tubular luminal connections between each other as could be revealed from serial sections: Figs. $4-6$ are subsequent ultrathin sections in such a series and tubular connections are, for instance, clearly identified in the upper and lower right part of the stack. Such intercisternal tubular connections were mostly seen in the periphery of stacks. Fig. 7 presents a situation where all cisternae of an AL stack periphery are in luminal continuity. The pore complexes (inner pore diameter $715 \pm 20 \AA$ ) were packed in these AL at an average frequency of 48 pores per square micron. They often were arranged in register across the whole stack with filamentous pore-to-pore connections (Figs. 5-7). Pore frequency values for the pollen mother cell nuclear envelope (inner pore diameter ca. $700 \pm 30 \AA$ ) are hard to give for comparison because pores can occur here in clusters whereas other areas of the nuclear surface are totally devoid of pores the latter being the case, e.g., in the section associated with nucleoli (Fig. 8; c.f. also LaCour and Wells, 1972). In those areas of the nuclear envelope with clustered pores the pore frequency is about the same as in the AL (52 pores $/ \mu^{2}$ ), so that the average pore frequency of the total nuclear envelope must be significantly lower than that of the AL.

The subarchitecture of the AL pore complexes is basically the same as in the pore complexes of the corresponding nuclear envelope (Fig. 10a). One recognizes in cross-sections through the perinuclear as well as through the annulate cisternae the annular subunits lying on both sides upon the pore margin (Fig. 10a, b). In the equatorial plane of a pore complex the "projecting tips" (Franke and Scheer, 1970) extend into the pore

Fig. 3. Higher magnification from Fig. 2, showing the pore complexes of the nucleus (in the left) and the AL. The small arrow at the top denotes transition between $\mathrm{AL}$ and ER. Note also small vesicles associated with $\mathrm{AL}$ pore complexes (e.g., at the long arrow in the top). The arrow in the lower right points to ribosomes attached to the AL membrane. The "aggregate complex" consisting of smooth vesicles and dense masses is marked by the pair of arrows. $\times 58000$ 


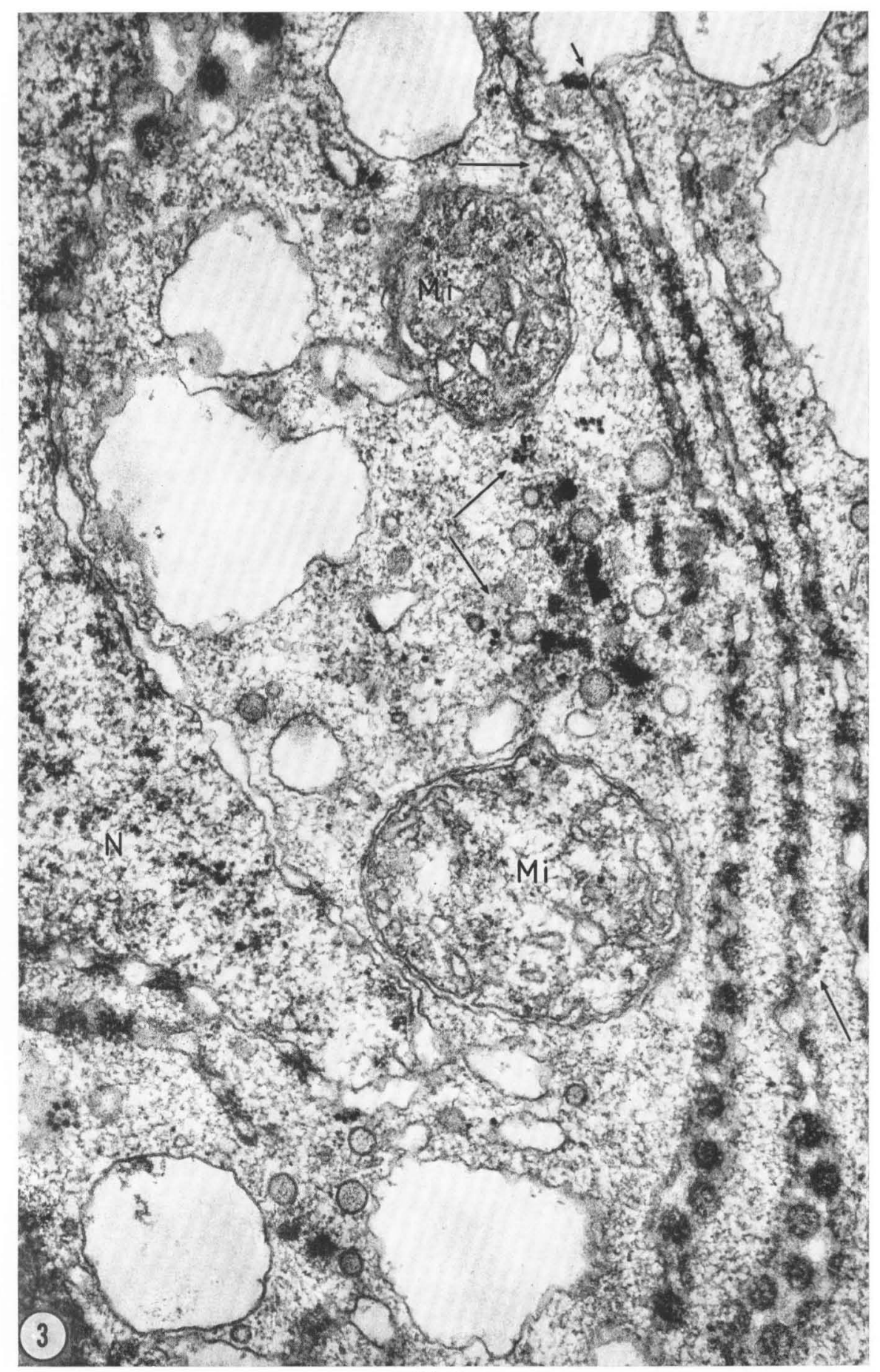

Fig. 3 
lumen thus leaving a "central channel" which is often occupied by granular or rod-shaped electron dense material (e.g. Fig. 10a, b). In sections grazing the AL or the nuclear envelope this centrally located material often appears as a "central granule" connected to the annular ring by fine fibrils (e.g. Figs. 3, 10e). The subunits which build up the annulus of the AL pores are clearly different from adjacent membrane attached ribosomes by their lower electron density (Fig. 10 c, g). "Annulus attached fibrils" extend from the nuclear pore complexes into the nucleoplasm as well as into the cytoplasm (Fig. 10a, e). Comparable fibrils interconnect the $\mathrm{AL}$ pore complexes of adjacent cisternae or span between pore complexes and adjacent AL membrane faces (Figs. 4-7, 10d, f, g). A similar connection between the annulus-attached fibrils of a nuclear pore complex and a cytoplasmic AL is demonstrated in Fig. 10e. In Fig. $10 \mathrm{~g}$ one recognizes a characteristic ribosome formation at an $\mathrm{AL}$ with a spatial arrangement highly resembling the arrangement and dimensions of pore substructures. Smooth surfaced vesicles are often closely attached to the $\mathrm{AL}$ membranes or pore complexes by fine filaments (e.g. Fig. 10f, g). A conspicuous association of a single AL stack with the forming face of a dictyosome is demonstrated in Fig. 14 (compare also Babbage and King, 1970; Maul, 1970).

Aggregates of dense tangles often showed a distinct association and fibrillar continuity with the AL (Fig. 13). These dense masses apparently can occur in different package stages (Figs. 11 and 12) and resemble in some respects cytological formations such as the heavy bodies (for literature see, e.g., Harris, 1967; Franke and Scheer, 1971), the spherical aggregates of oviduct fibrils hypothesized as being "aggregate pools" of microtubule-like proteins (Anderson and Brenner, 1971; Dirksen, 1971), the aggregates described in growing Lilium and Clivia pollen tubes by Franke et al. (1972), and the cytoplasmic "nucleoloids" described from anaphase I to young spores in Lilium (Dickinson and HeslopHarrison, 1970).

\section{Discussion}

The basic criterion for AL is not the stacking of a series of cisternae but the occurrence of characteristic pore complexes (for definition c.f., e.g., Watson, 1959; Franke, 1970). Stack formations of ER are very

Fig. 4. Stack of AL in the cytoplasm of a pollen mother cell of Canna. Note the nu. merous tubular connections between adjacent annulate cisternae (arrows). The lower arrow points to a single pore complex in a region of transition from $\mathrm{AL}$ to ER. Two dictyosomes $(D)$ are located close to the AL stack. Note the electron dense plug material in dictyosomal fenestrae (arrow in the upper right). $\times 37000$ 


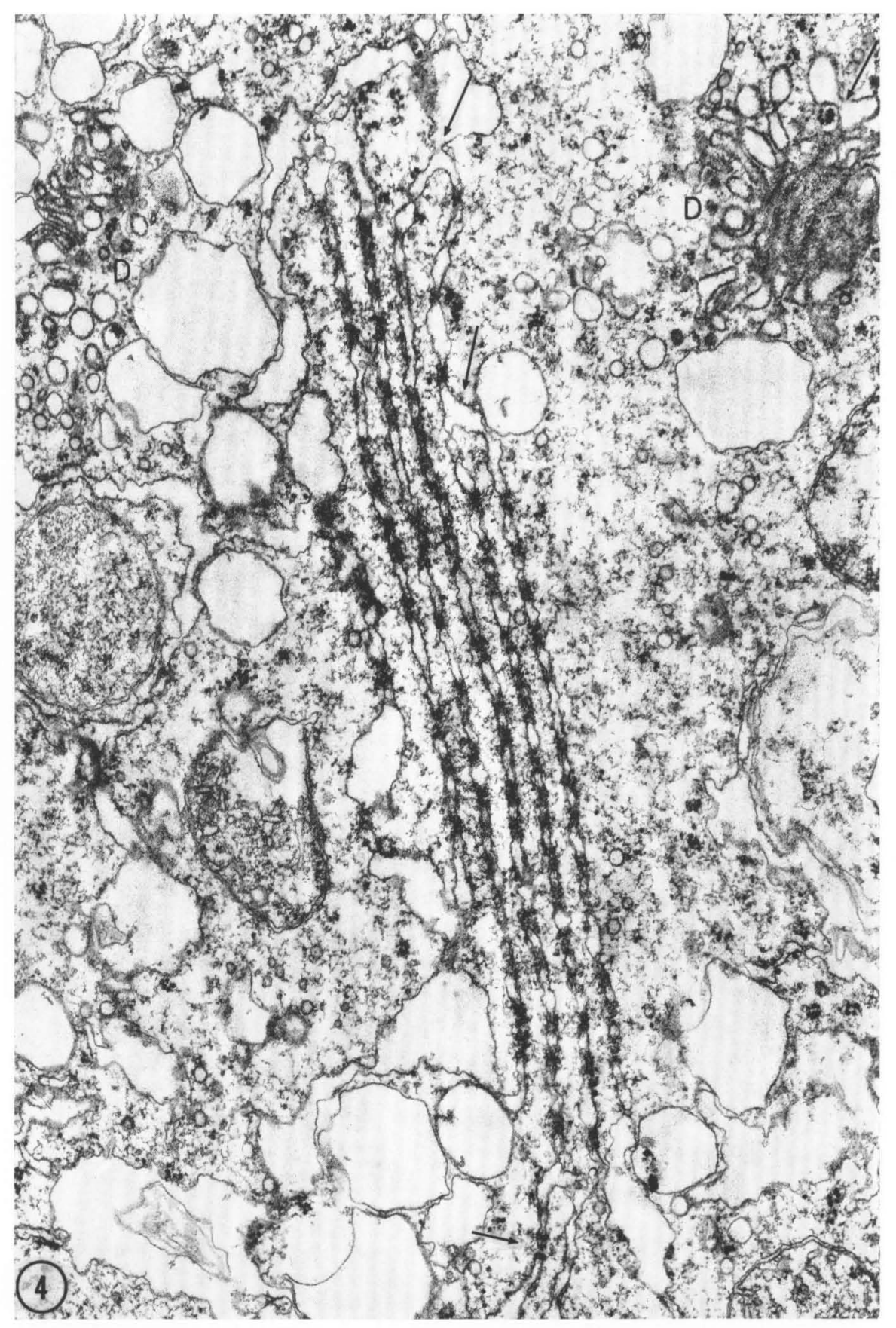

Fig. 4 
common in plant microsporogenesis (c.f. Ledbetter and Porter, 1970; Sen, 1970). The occurrence of pore complexes in such cisternae has until now not been documented for plant material, although Skvarla (quoted in the addendum to Kessel's review, 1968) and Sheridan and Barrnett (1969) have mentioned the existence of AL in meiocytes and in growing pollen of Lilium and Canna, respectively. We have recently shown that single annulate cisternae can be found in both the nucleoplasm and the cytoplasm of cultured plant cells (Franke et al., 1972). The present study which confirms the remark of Skvarla represents to our knowledge the first documentation of stacked AL in plant cells.

The plant AL have properties identical to those known from animal systems. This relates in particular to the following:

(i) They occur in both forms, single or integrated in stacks, with a stacking periodicity of $100 \mathrm{~nm}$.

(ii) The subarchitecture and dimensions of the pore complexes is identical to that known for the pore complexes of animal AL and nuclear envelope (Kessel, 1968; Stevens and Andre, 1969; Scheer and Franke, 1969; Franke, 1970; Wischnitzer, 1970).

(iii) The pore frequency of AL is very high (usually it is higher than the mean pore density of the nuclear envelope in the same cell, c.f. Hertig and Adams, 1967; Scheer and Franke, 1969; Maul, 1970).

(iv) There is a tendency of the pore complexes to be arranged in register across the stack, thereby being interconnected with fine pore-to-pore filaments (Kessel, 1968).

(v) The AL cisternae can bear ribosomes and are continuous with rough ER cisternae (Kessel, 1968).

(vi) They can exhibit a structural relationship to "heavy body like" aggregates thus resembling the classic situation in the sea urchin oocytes (e.g., Afzelius, 1957; Harris, 1967; Conway, 1971).

It is still an open question how AL form. Many authors favor the view that they originate from outfoldings of the nuclear envelope (e.g., Hsu, 1967; Bal et al., 1968; Gwynn et al., 1971). This is mainly based upon the conspicuous frequency of the AL relationship and continuity with the nuclear envelope. We have recently added to the current discussion on $\mathrm{AL}$ formation the alternative that they emerge directly from rough ER (Franke and Scheer, 1971; see also Hoage and Kessel, 1968).

Figs. 5 and 6 . Micrographs of sections which are in a section series thus allowing threedimensional reconstruction of the arrangement. Upper and lower arrows point to tubular connections between adjacent AL cisternae. The left arrows denote a luminal continuity between rough ER and AL. Frequently the pore complexes are arranged in register across the stack (e.g., at the pairs of arrows). $\times 43000$ 


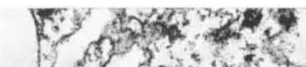
2.

Bute H.

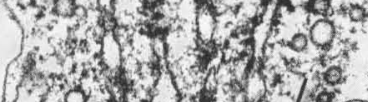

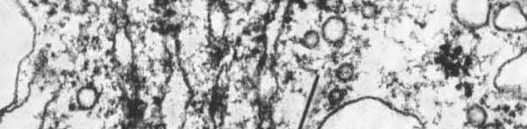

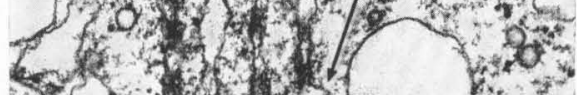

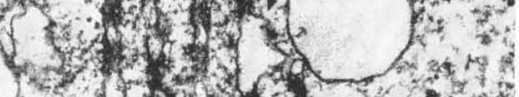
$\left\{\begin{array}{l}1 \\ 4\end{array}\right.$ $\left\{\begin{array}{l}1 \\ 4\end{array}\right.$ For

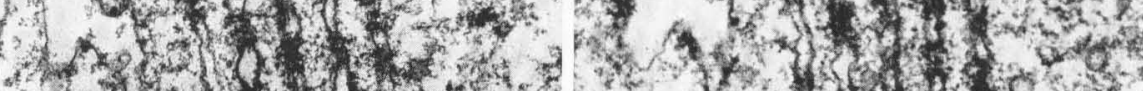

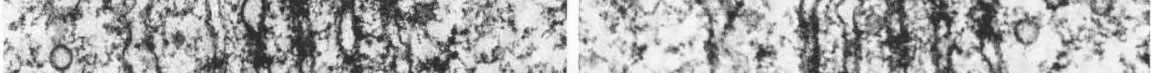

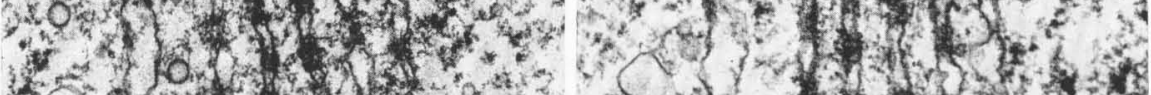

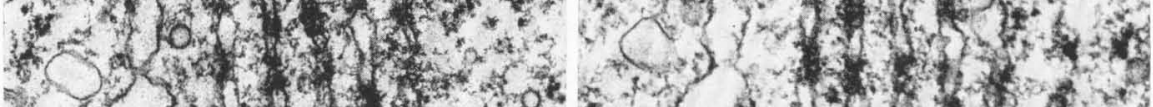

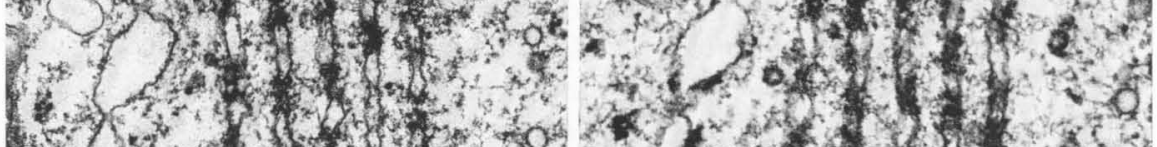

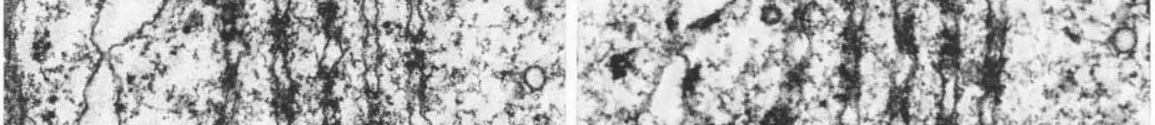

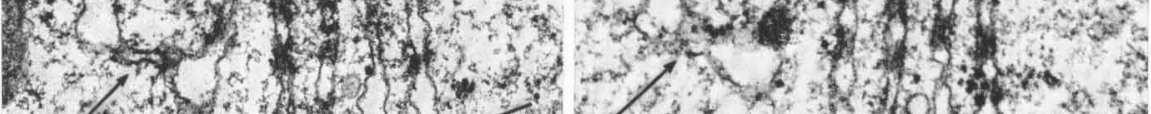

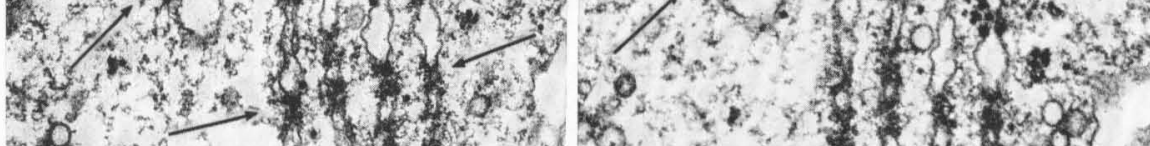

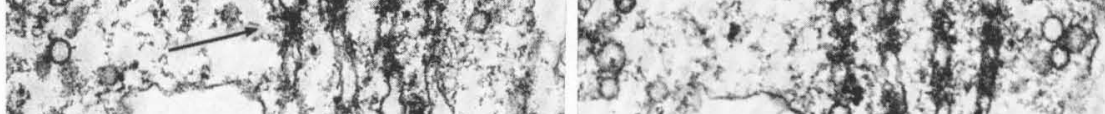

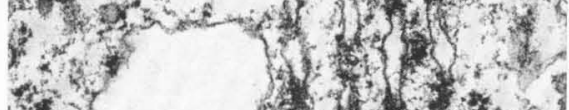

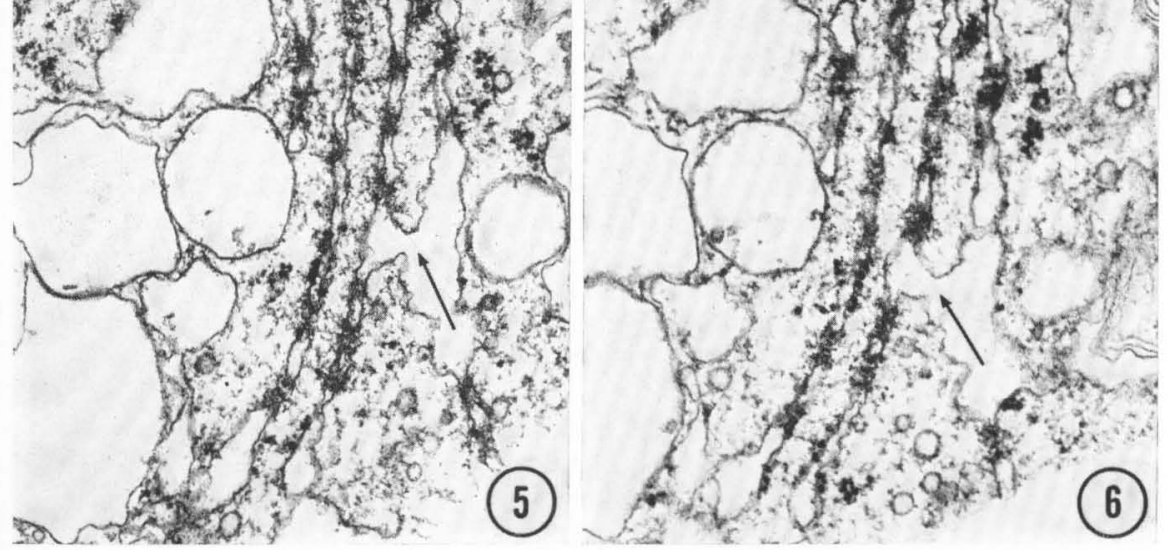

Figs. 5 and 6 
In this concept pore complexes would be the result of a local membrane breakage (c.f. Franke et al., 1971), possibly induced by alteration in composition and arrangement of membrane-bound ribosomes. Our study on plant AL contains some observations that would be in line with this view: first of all, AL membranes bear polysomes; second, cisternal membranes connect at sites of attachment of membrane bound ribosomes (c.f. Fig. $10 \mathrm{~g}$ ); third, the AL occur in parts of the cytoplasm which exhibit a general tendency for disappearance of membrane-bound and free ribosomes; and fourth, a characteristic type of vesicles is often associated with an AL pore (e.g., Fig. $10 \mathrm{~g})$. In particular as far as microsporogenesis is concerned it is interesting to note that there is a marked decrease in acid-insoluble RNA from leptotene to diakinesis (Dickinson and Heslop-Harrison, 1970). It is conceivable that AL pores originate from the following series of events: a rough ER ribosomal alteration induces a local change in membrane structure, possibly as a "phase transition" in the sense of Lucy (1970). This results in a membrane breakagerearrangement process of the type described by Franke et al. (1971) during which a vesicle and a pore are simultaneously produced. The pore is still associated with the ribosome-derived ribonucleoproteins, thus constituting the pore complex. In this hypothesis AL could be regarded as a "degenerative form of rough ER". This may mean that the AL do not necessarily have a particular function such as storage of ribosomal or messenger-type RNA as has been repeatedly envisaged in the literature (e.g., Verhey and Moyer, 1967; Bal et al., 1968; King and Richards, 1968; Babbage and King, 1970).

We thank Miss Sigrid Krien and Miss Marianne Winter for careful technical assistance as well as our colleague Dr. H. Falk for helpful discussions. We are indebted to Miss Patricia Reau (Lehrstuhl für Molekularbiologie, Freiburg i. Br.) for reading and correcting the manuscript.

Fig. 7. Another serial section to the AL stack shown in the previous figures. The annulate cisternae communicate with rough ER preferentially in the marginal parts of the stack (small arrows). Occasionally, the periphery of an AL stack is constituted by a common ER cisterna (e.g., at the bottom). Note the fibrillar interconnections between pore complexes and the serial arrangement of pores (pair of arrows in the center). $\times 42000$

Figs. 8 and 9. Characteristic features of the Canna pollen mother cells which contain AL stacks. Fig. 8 shows the nucleolus tightly pressed to the nuclear envelope. In this region pore complexes are obviously missing. $\times 51000$. Fig. 9 shows the presence of a typical synaptinemal complex in this material. $\times 54000$ 

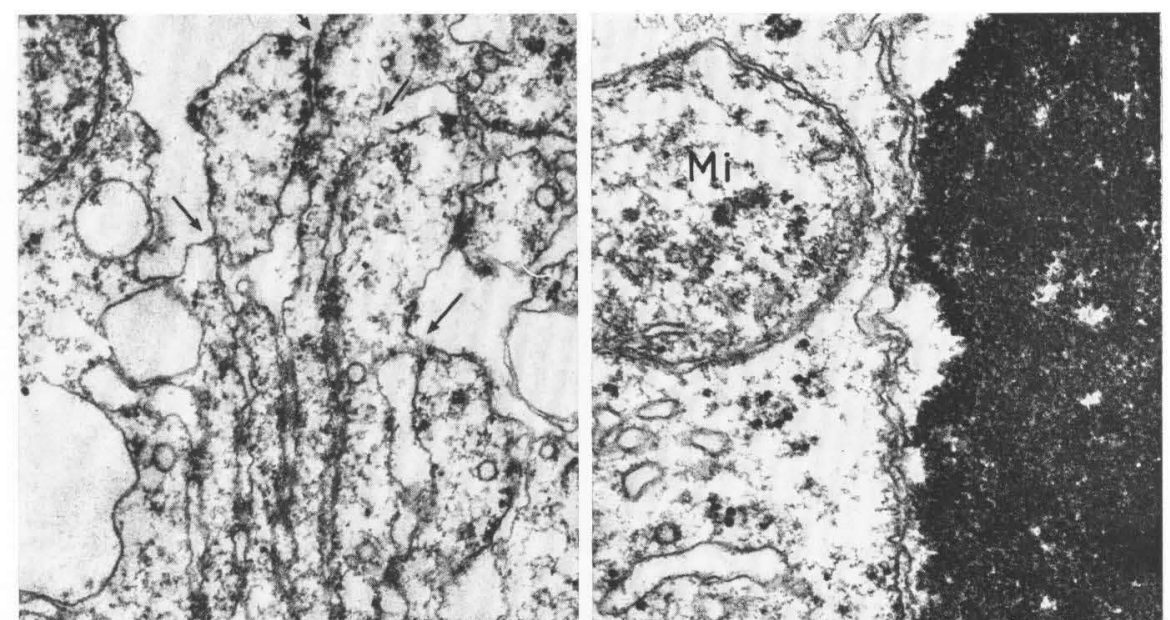

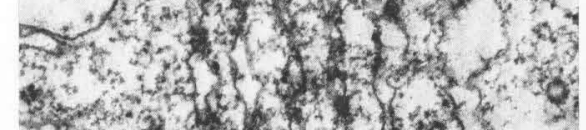

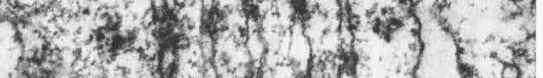

1.

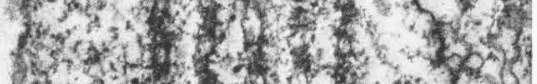

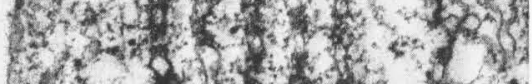

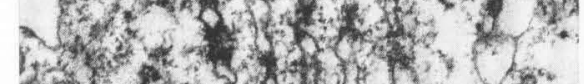

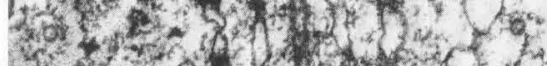

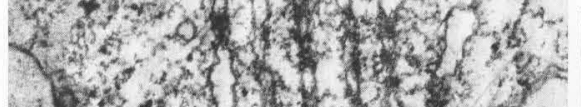

3.t.

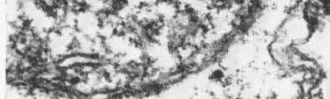

$x^{2}+1$

$x^{4} y^{2}+z^{2}+x^{2}$

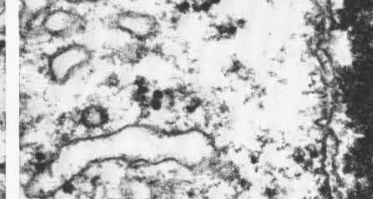

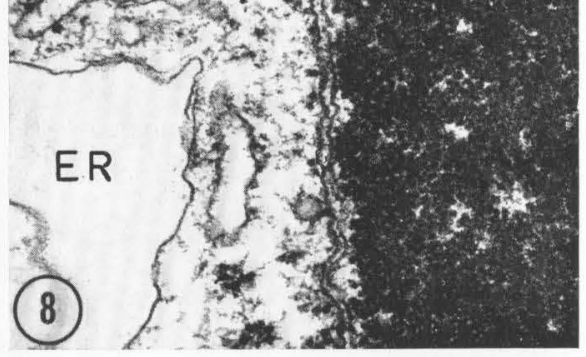

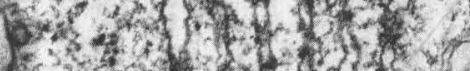

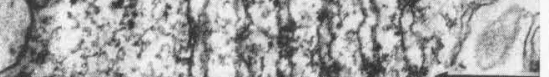

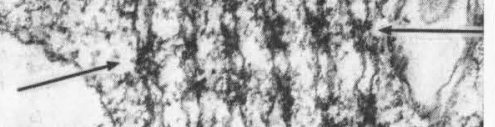

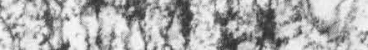

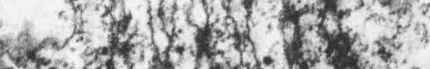

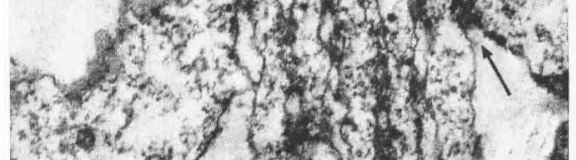

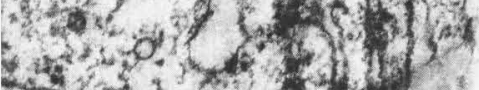
$x \rightarrow 3,2,12,1$

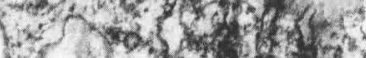

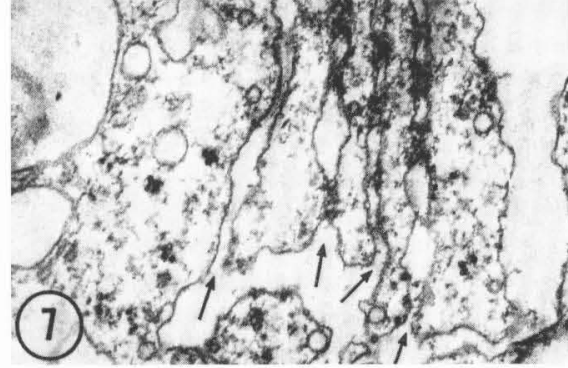

4

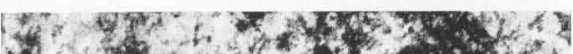
$12+2+x^{2}+3 x+3 x^{2}$ 130 -

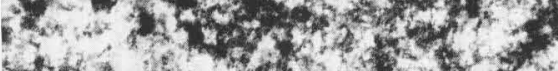

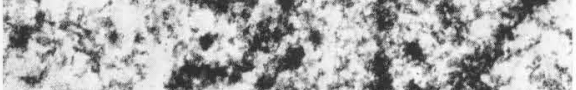

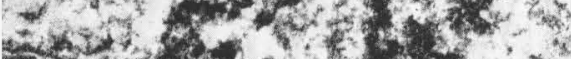

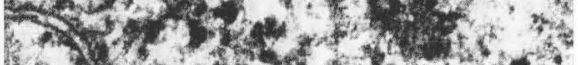

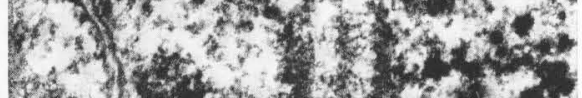

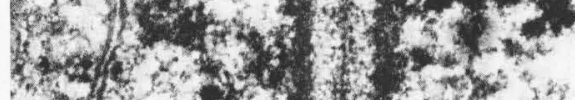

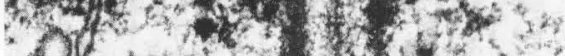

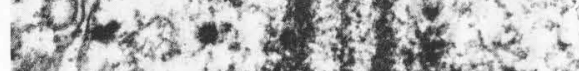

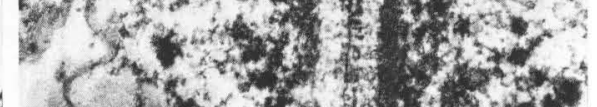

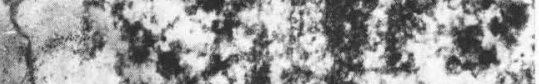

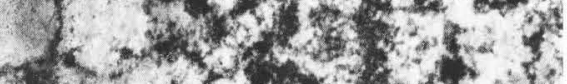

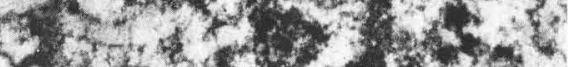

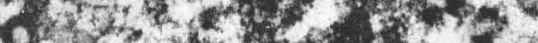

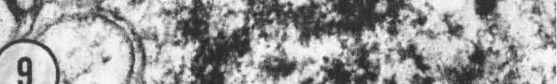

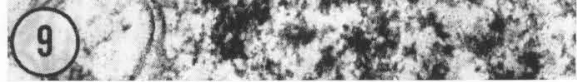




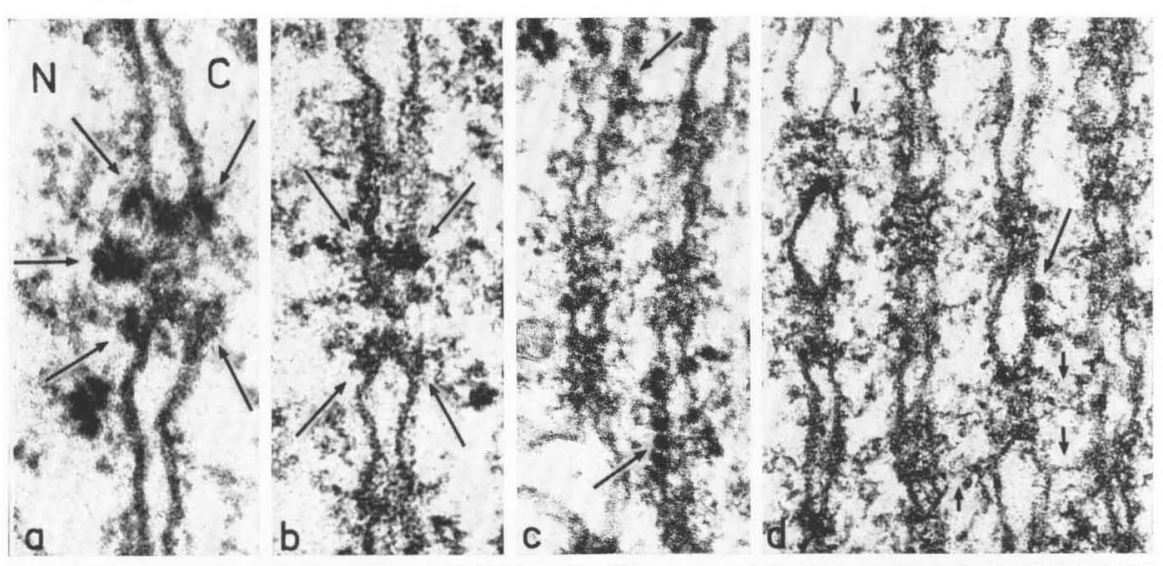

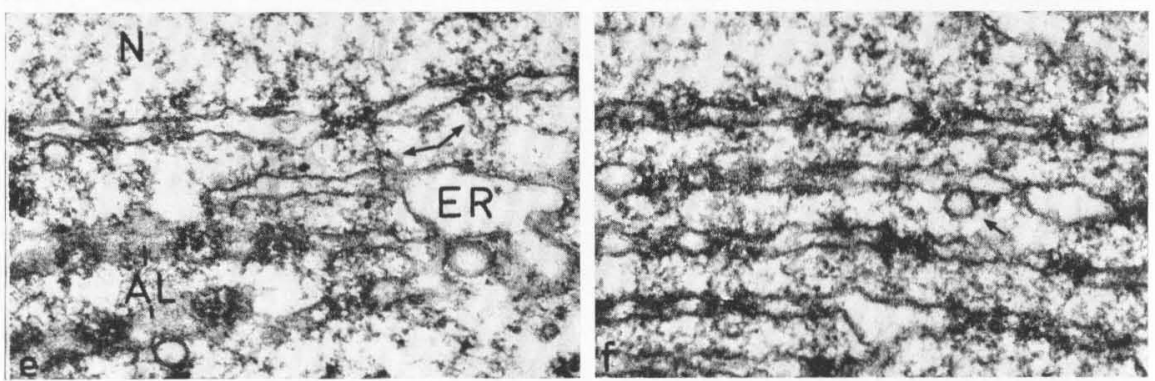

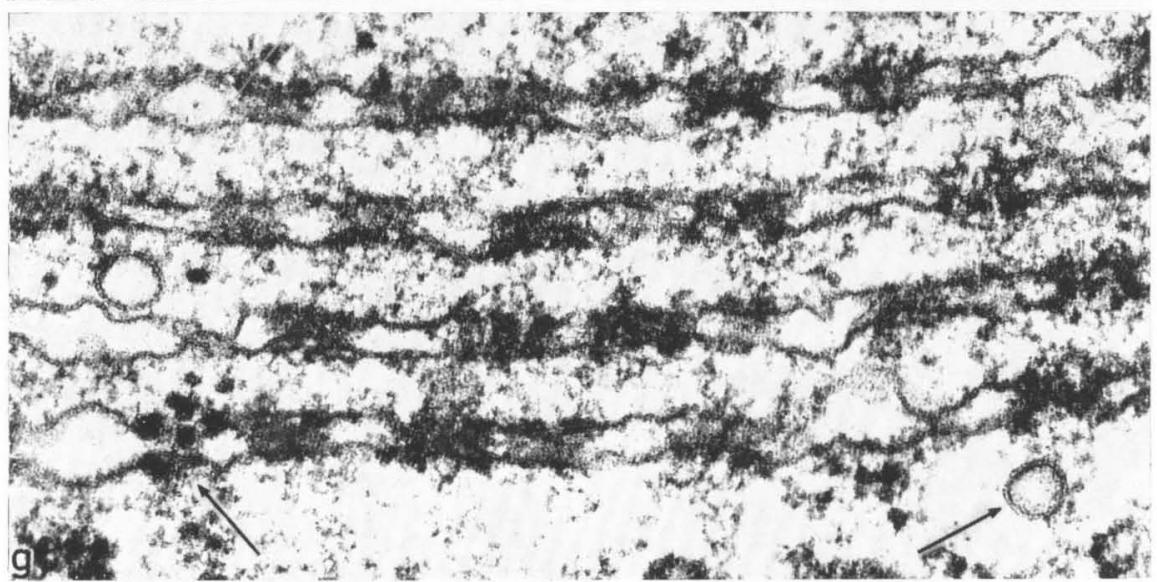

Fig. $10 \mathrm{a}-\mathrm{g}$. Subarchitectural details of pore complexes of the nuclear envelope (a) and AL (b) in Canna pollen mother cell. Note the annular subunits (arrows), the "projecting tips" at the pore walls and the "central granule" material (e.g., at the arrow in a). Ribosomes (arrows in $\mathrm{c}$ and $\mathrm{d}$ ) attached to the $\mathrm{AL}$ membrane appear to be more compact and show higher electron density than the pore complex constituents. Fig. d shows fibrils spanning between pore complexes of adjacent annulate cisternae (arrowheads). Fibrillar connections between a nuclear pore complex and the ER-AL cisternal system are seen in Fig. e. Fig. f gives an impression of abundance of finely filamentous material filling the spaces between adjacent AL cisternae. Small smooth surfaced vesicles are sometimes associated with the AL membranes and pore complexes, respectively, often connected by fine filaments 


\section{References}

Afzelius, B. A.: Electron microscopy on the basophilic structures of the sea urchin egg. Z. Zellforseh. 45, 660 675 (1957).

Anderson, G. W., Brenner, R. M.: The formation of basal bodies (centrioles) in rhesus monkey oviduct. J. Cell Biol. 50, 10-34 (1971).

Babbage, P. C., King, P. E.: Post-fertilization functions of annulate lamellae in the periphery of the egg of Spirorbis borealis (Daudin) (Serpulidae=Annelida). Z. Zellforsch. 107, 15-22 (1970).

Bal, A. K., Jubinville, F., Cousineau, G. H., Inoué, S.: Origin and fate of annulate lamellae in Arbacia punctulata eggs. J. Ultrastruct. Res. 25, 15-28 (1968).

Barnes, B. G., Davis, J. M. : The structure of nuclear pores in mammalian tissues. J. Ultrastruct. Res. 3, 131-146 (1959).

Conway, C. M.: Evidence for RNA in the heavy bodies of sea urchin eggs. J. Cell Biol. 51, 889-893 (1971).

Dickinson, H. G., Heslop-Harrison, J.: The ribosome cycle, nucleoli, and cytoplasmic nucleoloids in the meiocytes of Lilium. Protoplasma (Wien) 69, 187-200 (1970).

Dirksen, E. R.: Centriole morphogenesis in developing ciliated epithelium of the mouse oviduct. J. Cell Biol. 51, 286-302 (1971).

Franke, W. W.: On the universality of nuclear pore complex structure. Z. Zellforsch. 105, 405-429 (1970).

Franke, W. W., Eckert, W. A., Krien, S.: Cytomembrane differentiation in a ciliate, Tetrahymena pyriformis. I. Endoplasmic reticulum and dictyosomal equivalents. Z. Zellforsch. 119, 577-604 (1971).

Franke, W. W., Herth, W., Van Der Woude, W. J., Morré, D. J.: Tubular and filamentous structures in pollen tubes: possible involvement as guide elements in protoplasmic streaming and vectorial migration of secretory vesicles. Planta (Berl.) 105, 317-341 (1972).

Franke, W. W., Scheer, U.: The ultrastructure of the nuclear envelope of amphibian oocytes: a reinvestigation. I. The mature oocyte. J. Ultrastruct. Res. 30, 288-316 (1970).

Franke, W. W., Scheer, U.: Some structural differentiations in the HeLa cell: heavy bodies, annulate lamellae, and cotte de maille endoplasmic reticulum. Cytobiol. 4, 317-329 (1971).

Franke, W. W., Scheer, U., Fritsch, H.: Intranuclear and cytoplasmic annulate lamellae in plant cells. J. Cell Biol. 53, 823-827 (1972).

Gwynn, I., Barton, R., Jones, P. C. T.: Formation and function of cytoplasmic annulate lamellae in the eggs of Pomatoceros triqueter L. Z. Zellforsch. 112, 390-395 (1971).

Harris, P.: Structural changes following fertilization in the sea urchin egg. Exp. Cell Res. 48, 569-581 (1967).

Hertig, A. T., Adams, E. C.: Studies on the human oocyte and its follicle. I. Ultrastructural and histochemical observations on the primordial follicle stage. J. Cell Biol. 34, 647-675 (1967).

Hoage, T. R., Kessel, R. G.: An electron microscope study of the process of differentiation during spermatogenesis in the drone honey bee (Apis mellifera L.) with special reference to centriole replication and elimination. J. Ultrastruct. Res. 24, 6-32 (1968).

Hsu, W. S.: The origin of annulate lamellae in the oocyte of the Ascidian, Boltenia villosa Stimpson. Z. Zellforsch. 82, 376-390 (1967).

Kessel, R. G.: Annulate lamellae. J. Ultrastruct. Res., Suppl. 10, 1-82 (1968). 
King, P. E., Richards, J. G.: Accessory nuclei and annulate lamellae in hymenopteran oocytes. Nature (Lond.) 218, 488 (1968).

LaCour, L. F., Wells, B.: The nuclear pores of early meiotic prophase nuclei of plants. Z. Zellforsch. 123, 178-194 (1972).

Ledbetter, M. C., Porter, K. R.: Introduction to the fine structure of plant cells. Berlin-Heidelberg-New York: Springer 1970.

Lucy, J. A.: The fusion of biological membranes. Nature (Lond.) 227, 815-817 $(1970)$.

Maul, G. G.: On the relationship between the Golgi apparatus and annulate lamellae. J. Ultrastruct. Res. 30, 368-384 (1970).

Moens, P. B.: The structure and function of the synaptinemal complex in Lilium longiflorum sporocytes. Chromosoma (Berl.) 23, 418-451 (1968).

Pollister, A. W., Gettner, M., Ward, R. Nucleocytoplasmic interchange in oocytes. Science 120, 789 (1954).

Scheer, U., Franke, W. W.: Negative staining and adenosine triphosphatase activity of annulate lamellae of newt oocytes. J. Cell Biol. 42, 519-533 (1969).

Sen, S. K.: Nuclear membrane and cytoplasmic lamellae at meiotic prophase of Lilium microsporocytes. Cytologia (Tokyo) 35, 368-377 (1970).

Sheridan, W. F., Barrnett, R. J.: Cytochemical studies on chromosome ultrastructure. J. Ultrastruct. Res. 27, 216-229 (1969).

Stevens, B.J., André, J.: The nuclear envelope. In: Handbook of molecular eytology (A. Lima-De-Faria, ed.), p. 837-871. Amsterdam: North-Holland-Publishing Comp. 1969.

Verhey, C. A., Moyer, F. H.: Fine structural changes during sea urchin oogenesis. J. exp. Zool. 164, 195-207 (1967).

Watson, M. L.: Further observations on the nuclear envelope of animal cells. J. biophys. biochem. Cytol. 6, 147-155 (1959).

Wischnitzer, S.: The annulate lamellae. Int. Rev. Cytol. 27, 65-100 (1970).

Ulrich Scheer

Werner W. Franke

Institut für Biologie II

Lehrstuhl für Zellbiologie

D-7800 Freiburg i. Br.

Schänzlestr. 9

Germany 